\title{
REPRESENTAÇÕES DO TRABALHO ENTRE TRABALHADORES INFORMAIS DA CONSTRUÇÃO CIVIL ${ }^{1}$
}

Roberval Passos de Oliveira* Jorge Alberto Bernstein Iriart"

\begin{abstract}
RESUMO. O presente estudo buscou compreender as representações do trabalho entre trabalhadores informais da construção civil. Foi adotada como referencial teórico a Teoria das Representações Sociais. Diante da complexidade do problema de pesquisa abordado, fez-se uso de múltiplas técnicas de coleta de dados: entrevistas em profundidade com oito trabalhadores e observação participante. Os resultados revelaram que o trabalho é representado como uma dimensão central na vida dos trabalhadores, subsidiando a sobrevivência material e social. Entretanto, o trabalho na construção civil foi descrito como pesado e desvalorizado, aparentando constituir-se como "último recurso" buscado para garantir a sobrevivência. Os trabalhadores reconhecem a precarização do trabalho gerada pela inserção informal, sentindo-se inferiorizados em relação aos trabalhadores formais. Tal quadro demonstra como os trabalhadores informais vivenciam um tipo de violência que lhes cerceia o usufruto de direitos constitucionalmente assegurados, excluindo-os do pleno gozo da cidadania.
\end{abstract}

Palavras-chave: representação social, trabalho informal, construção civil.

\section{THE REPRESENTATION OF WORK AMONG IRREGULAR CONSTRUCTION WORKERS}

\begin{abstract}
The social representation of work among irregular construction workers is analyzed. The Social Representation Theory has been employed as a theoretical framework for current investigation. Due to the complexity of the research problem, multiple techniques of data collection were used, comprising in-depth interviews with eight workers and participants' observation. Results show that work is a main factor within the worker's life, basic to social and material survival. Although, construction labor was described as heavy and downgrading, it seems to be the "latest resource" for survival. The workers recognize the precariousness generated by irregularity since they feel inferior to formal workers. This situation denotes that construction workers experience a kind of violence that leaves them out of assured constitutional rights and full citizenship.
\end{abstract}

Key words: Social representation, informal job, construction.

\section{REPRESENTACIONES DEL TRABAJO EN TRABAJADORES INFORMALES EN LA CONSTRUCCIÓN CIVIL}

RESUMEN. El presente estudio buscó comprender las representaciones sobre trabajo en trabajadores informales en la construcción civil. Fue adoptada como referencial teórico la Teoría de las Representaciones Sociales. Debido a la complejidad del problema de investigación abordado, se hizo uso de varias técnicas de colecta de datos: entrevistas en profundidad con ocho trabajadores, y observación participante. Los resultados muestran que el trabajo es representado como una dimensión central en la vida de los trabajadores, la cual subsidia la supervivencia material y social. De tal forma, el trabajo en la construcción civil fue descrito como pesado y desvalorizado, aparentando ser el "último recurso" buscado para garantizar la supervivencia. Los trabajadores reconocen una precarización del trabajo generada por la inserción en el sector informal, sintiéndose inferiores en relación a los trabajadores del sector formal. Este cuadro demuestra como los trabajadores del sector informal pasan por un tipo de violencia, que les impide el aprovechamiento de derechos constitucionales asegurados, excluyéndolos del goce pleno de la ciudadanía.

Palabras-clave: Representación social, trabajo informal, construcción civil.

\footnotetext{
Apoio: CNPq/PIBIC, CAPES.

* Doutor em Saúde Pública. Professor adjunto do Centro de Ciências da Saúde-CCS da Universidade Federal do Recôncavo da Bahia-UFRB.

\# Doutor em Antropologia. Professor adjunto do Instituto de Saúde Coletiva-ISC da Universidade Federal da Bahia-UFBA.
} 
Apesar de alguns autores, como Offe (1994). e Gorz (1982), afirmarem a perda da centralidade do trabalho e a tendência ao fim do emprego, o trabalho ainda representa um valor moral, algo central na vida das pessoas, que subsidia tanto a sobrevivência material como a social (Sarti, 1996; Zaluar, 1994). Contra a idéia do fim do trabalho, Sorj (2000). argumenta que o trabalho, em sua pluralidade de formas, continua a se configurar como um importante determinante das condições de vida das pessoas, invadindo de tal forma diferentes esferas da vida, que, por vezes, torna-se difícil estabelecer as fronteiras entre o trabalho e o não-trabalho. Castel (1998b) também não comunga a tese do fim da sociedade do trabalho, colocando que a relação com o trabalho se alterou, mas é ainda sobre ele que continua a desenrolar-se o destino das pessoas.

Pode se afirmar que, como aponta Sorj (2000), ocorreu uma grande mudança em relação ao regime de emprego que prevaleceu nas sociedades avançadas desde o Pós-Guerra - período chamado de a idade de ouro do capitalismo. Denominado por Castel (1998a) de sociedade salarial, esse momento histórico se caracterizou por um alto grau de padronização em vários aspectos, como o contrato de trabalho, o lugar do trabalho e a duração da jornada de trabalho. Buscava-se combinar trabalho e proteção, concedendo à condição de assalariado não apenas uma retribuição monetária em forma de salário, mas certo número de garantias e de direitos. Nesse sentido, Castel (1998b) afirma que havia um "salário indireto", destinado a prover as despesas dos trabalhadores nos momentos de suspensão provisória da atividade, em caso de acidente ou doença, assim como por ocasião da cessação definitiva do trabalho (a aposentadoria).

Nos dias de hoje, os novos postos tendem a ser flexíveis no tempo, no espaço e na duração, dando origem a uma grande variedade de contratos de trabalho. Embora o desemprego constitua a expressão mais visível da mudança na conjuntura do emprego, é a precarização do trabalho a sua característica mais relevante (Castel, 1998a). De acordo com Azevedo (1999) e Montali (2000), as regiões metropolitanas de Salvador e São Paulo, respectivamente, vêm sofrendo as conseqüências desse processo, materializadas na redução dos postos de trabalho e na flexibilização das relações de trabalho.

Todos esses fatores, que integram a realidade do mundo do trabalho na atualidade, incrementam o número de indivíduos que passam a buscar sua subsistência através de um trabalho informal, na maioria das vezes em condições totalmente insalubres e inseguras, executando os serviços mais arriscados e perigosos.

\section{O TRABALHO INFORMAL}

O conceito de trabalho informal congrega em si uma série de atividades e formas distintas de inserção no mundo do trabalho. Estão aí incluídos tanto proprietários de pequenas estruturas produtivas quanto aqueles trabalhadores que operam total ou parcialmente na ilegalidade (Filgueiras, Druck \& Amaral, 2004). Pela controvérsia que envolve a discussão sobre o termo informalidade, esse comporta múltiplos significados e usos, propiciando a coexistência de grande variedade de abordagens sobre a questão.

Em virtude de sintetizarem fenômenos econômicos bastante heterogêneos, os distintos conceitos de informalidade, se não definidos teórica e operacionalmente, podem dificultar a compreensão da estrutura e dinâmica do mercado de trabalho. Mediante esse mote, Filgueiras et al. (2004), baseados em diversos estudos sobre o tema, apresentam três conceitos de informalidade, a partir de dois critérios: o primeiro diferencia o formal do informal a partir das respectivas lógicas de funcionamento das atividades se tipicamente capitalistas ou não; enquanto o segundo delimita essa dessemelhança de acordo com a legalidade ou ilegalidade das atividades.

No presente estudo, adotou-se o conceito de informalidade a partir da junção dos dois critérios apresentados por Filgueiras et al. (2004), definindo a condição de informal como aquela em que o trabalhador executa um trabalho que não é trocado por capital e não contribui diretamente para aumentar o capital e/ou que não possui um vínculo de trabalho regulamentado. Essa conceituação compreende tanto atividades e formas de produção não tipicamente capitalistas - legais ou ilegais - quanto relações de trabalho não registradas, mesmo que tipicamente capitalistas.

As pessoas que se vêem incluídas nessa problemática são, geralmente, de menor escolaridade, de baixa qualificação profissional, negros, jovens e mulheres (Barros \& Mendonça, 1996; Fagundes, 1994). Alguns autores apontam para a idéia de que o percurso dessas pessoas para atividades do ramo informal seria uma opção, uma busca por melhores rendimentos e maior liberdade de atuação profissional (Menezes \& Carrera-Fernandez, 1998). Todavia, conforme inquérito de base populacional realizado em Salvador (Santana \& Oliveira, 2004), a condição de trabalhador informal não parece ser uma escolha para os trabalhadores da construção civil: mais da metade dos entrevistados mencionaram "falta de oportunidade" como motivo para não ter contrato 
formal de trabalho, sentindo-se prejudicados pela falta da aposentadoria remunerada.

Diante do aumento do número de trabalhadores informais convivendo com condições precárias de trabalho, o presente estudo teve como objetivo compreender como esses trabalhadores representam o trabalho. Entende-se que, a partir da visão dos próprios atores envolvidos nesse contexto, torna-se possível produzir conhecimentos que fundamentem ações concernentes à melhoria das condições de trabalho, através da instituição de práticas culturalmente apropriadas. Nessa perspectiva, elegeuse como foco de investigação o ramo da construção civil pelo fato de que ele ilustra bem tal realidade.

\section{A INDÚSTRIA DA CONSTRUÇÃO CIVIL}

Ramo de atividade de grande importância no cenário econômico brasileiro, a construção civil apresenta um percentual de apenas $20,1 \%$ de trabalhadores com carteira de trabalho assinada (DIEESE, 2001). Santana e Oliveira (2004) corroboram esses dados quando concluem que o trabalho informal parece se constituir em uma importante característica da precarização do trabalho nesse ramo de atividade. Esses autores encontraram uma maior proporção de trabalhadores sem contrato formal de trabalho na construção civil em comparação com outros ramos de atividade, o que evidencia a perda de direitos sociais, trabalhistas e previdenciários.

A presença marcante do trabalho informal na indústria da construção deriva, em parte, da utilização de mecanismos de rebaixamento de custos, a exemplo da subcontração de empresas (DIEESE, 2001; SESI, 1998). Essa prática envolve a contratação de empresas, em sua maioria de pequeno porte, que operam à margem da legislação trabalhista, conseguindo, por isso, apresentar propostas a preços reduzidos.

As mudanças nos padrões de uso da força de trabalho, promovidas pelos processos de reestruturação produtiva e de globalização da economia (Borges \& Druck, 1993), têm intensificado o trabalho informal e a rotatividade da força de trabalho empregada no ramo. Esta última permite a formação de um exército de reserva e possibilita que as firmas economizem com o não-pagamento de direitos trabalhistas, como o fundo de garantia por tempo de serviço, férias e aviso prévio (SESI, 1998).

Esse ramo apresenta peculiaridades que refletem uma estrutura dinâmica e complexa. Uma de suas características, discutida pelo SESI (1998), é o fato de os produtos gerados serem únicos (não-homogêneos e não-seriados), o que leva à execução de projetos singulares. Ademais, existe uma descontinuidade das atividades produtivas, definida pela fragmentação da produção em etapas e fases predominantemente sucessivas. Como conseqüência, o trabalho manual ainda se constitui na "mola-mestra" do processo produtivo, dificultando a introdução de máquinas e equipamentos.

A força de trabalho empregada na construção civil compõe-se, predominantemente, de indivíduos jovens, do sexo masculino, com baixa escolaridade, reduzida qualificação profissional, e por expressivo contingente de migrantes (DIEESE, 2001; Ringen, Seegal \& Weeks, 1998). Por conseguinte, esses trabalhadores apresentam os menores níveis de remuneração entre os demais ramos da indústria, o que lhes impõe a necessidade de estender a jornada de trabalho através da realização de horas extras ou da adoção de regime de tarefas (SESI, 1998).

Ao lado da importância real que representa para a economia mundial, o ramo da construção civil abriga uma dura realidade: é considerado um dos mais perigosos em todo o mundo, liderando as taxas de acidentes de trabalho fatais, não fatais e anos de vida perdidos (Ringen et al., 1998). Estudos apontam a construção civil como um dos ramos de atividade econômica com maior ocorrência de acidentes de trabalho (Santana, Nobre \& Waldvogel, 2005; Santana \& Oliveira, 2004). Ademais, outros agravos comuns aos trabalhadores desse ramo, como o alcoolismo, doenças mentais e doenças psicossomáticas, podem ser tomados como sintomas do sofrimento provocado pelo trabalho (Borges \& Martins, 2004).

Diante desse cenário, é possível apreender que a grande maioria dos trabalhadores da construção civil convive com características da informalidade, sendo afetada por esse traço de precarização do trabalho.

\section{TEORIA DAS REPRESENTAÇÕES SOCIAIS}

Neste artigo, parte-se do pressuposto de que as representações de objetos e questões socialmente relevantes são construídas pelo conjunto de percepções, sentimentos, normas e valores que permeiam as experiências individuais e coletivas, como também pela dinâmica das relações sociais estabelecidas em um dado contexto. Diante dessa perspectiva, tomou-se como referencial teórico a Teoria das Representações Sociais, de acordo com Moscovici (1978), o qual define representação social como "uma modalidade de conhecimento particular que tem por função a elaboração de comportamentos e 
a comunicação entre indivíduos" (p. 26). Esse conceito traz a noção de um sistema elaborado socialmente, que intervém na definição da identidade social, concretiza-se nas práticas e permeia atitudes e visões de mundo.

Para esse autor, representar um objeto não se resume em desdobrá-lo, repeti-lo ou reproduzi-lo; é ir mais além, é construir uma teoria destinada à interpretação e elaboração do real, que torne a realidade inteligível. Tal processo implica uma verdadeira reconstrução do objeto em um contexto de valores, noções e regras, de que esse se torna solidário. Como o dado externo não é algo acabado e unívoco, deixa muita liberdade para a atividade mental que se empenha em apreendê-lo. "A linguagem aproveita-se disso para circunscrevê-lo, para arrastá-lo no fluxo de suas associações, para impregná-lo de suas metáforas e projetá-lo em seu verdadeiro espaço, que é simbólico" (Moscovici, 1978, p. 26). Isso faz com que a comunicação e a linguagem possam ser consideradas como constitutivas do sujeito e de suas representações.

Seguindo esse raciocínio, Spink (1995b) refere que as representações sociais apresentam-se como um fenômeno complexo que decorre da desconstrução, no nível teórico, da falsa dicotomia entre o individual e o coletivo. Elas não são produzidas individualmente, são criadas dentro de determinadas culturas, próprias de determinados lugares. Os indivíduos que as elaboram pertencem a um determinado grupo, possuindo uma história de vida que é pessoal e social ao mesmo tempo. As respostas individuais expressam tanto a singularidade daquele que as propõem quanto as referências culturais do grupo do qual o indivíduo participa. É necessário entender como o pensamento individual se enraíza no social e como um e outro se modificam mutuamente.

Wagner (1998) corrobora esse entendimento ao afirmar que, nas relações sociais, as pessoas expressam e confirmam suas crenças, fazendo com que as representações se tornem uma unidade do que pensam e do modo como o fazem. Nessa perspectiva, uma representação é mais do que uma imagem estática de um objeto na mente, ela compreende também seu comportamento e a prática interativa de um grupo.

\section{CONSIDERAÇÕES METODOLÓGICAS}

A presente pesquisa, caracterizada como um estudo de caso, teve como população de estudo oito trabalhadores informais acidentados da construção civil, identificados na base de um estudo de coorte, conduzido com 9.551 pessoas, de uma amostra de residentes da cidade de Salvador - BA. Tal investigação foi concebida mediante um componente epidemiológico, que investigou as relações entre as condições de trabalho e saúde; e outro etnográfico, que objetivou produzir conhecimento acerca do trabalhador informal acidentado e sua relação subjetiva com o trabalho. $\mathrm{Na}$ etapa basal do componente epidemiológico foram identificados 300 trabalhadores que referiram acidentes de trabalho nos últimos 12 meses. Dentre esses, foram selecionados como interlocutores-chave todos os acidentados que trabalhavam na construção civil sem contrato formal de trabalho. Identificaram-se nove trabalhadores, dentre os quais um trabalhador se recusou a participar da pesquisa.

Diante da complexidade do problema abordado, fez-se uso de múltiplas técnicas de coleta de dados. Além de entrevistas em profundidade com trabalhadores, foram realizadas: entrevista com representante do Sindicato dos Trabalhadores da Indústria da Construção e Madeira SINTRACOM/BA; observação participante, acompanhando um trabalhador, no seu trabalho, durante três dias, e um auditor fiscal da Delegacia Regional do Trabalho - DRT em fiscalização a 18 canteiros de obras. Essa estratégia possibilitou uma imersão no mundo do trabalho da construção civil, enriquecendo o contexto a partir do qual foram interpretadas as falas dos trabalhadores entrevistados.

As entrevistas em profundidade foram desenvolvidas em três encontros com cada um dos trabalhadores - homens de cor negra ou mulata, com baixa escolaridade e idades que variavam entre $19 \mathrm{e}$ 61 anos -, em suas residências, mediante roteiros semi-estruturados. Os relatos foram gravados, realizando-se posterior transcrição. O programa QSR NUD-IST versão N-Vivo foi utilizado para facilitar a organização dos dados conforme as categorias que orientaram a análise: representações sobre o trabalho; representações sobre os chefes e patrões; representações sobre as condições de trabalho; representações sobre o trabalho informal; e trajetórias ocupacionais.

Como a condição sine qua non para a ação e o discurso é a pluralidade humana (Jovchelovitch, 1995), os discursos dos trabalhadores foram analisados e se identificaram suas peculiaridades, características intrínsecas e os aspectos de aparente consistência ou contradição. $\mathrm{O}$ entendimento da coexistência de permanência e diversidade no campo de estudo das representações sociais permite entender 
melhor o papel da contradição na elaboração das representações (Spink, 1995a).

Para a realização da coleta de dados foi assinado um termo de consentimento livre e esclarecido, através do qual os participantes atestaram a sua concordância em participar da pesquisa. $\mathrm{O}$ projeto de pesquisa que originou este artigo foi aprovado pelo Comitê de Ética do Instituto de Saúde Coletiva (Prot. No. 006-03/CEP-ISC, Parecer No. 033, 7/4/2003). Foram utilizados nomes fictícios para assegurar a privacidade e o sigilo quanto às identidades dos trabalhadores.

\section{RESULTADOS E DISCUSSÃO}

O trabalho foi definido pelos trabalhadores como uma dimensão central em suas vidas. Vários significados foram atribuídos ao trabalho, remetendo a diferentes funções que esse desempenha para os indivíduos. A função econômica, que se refere à sobrevivência material e à possibilidade de adquirir bens de consumo (Salanova, Gracia \& Peiró, 1996), foi a que mais se fez presente nos relatos. Esses resultados corroboram diversos estudos (Mourão \& Borges-Andrade, 2001; Sarti, 1996; Zaluar, 1994), demonstrando que, apesar da discussão sobre a perda da centralidade do trabalho, este continua sendo um valor moral, sem o qual a sobrevivência é impossível: "... hoje todo mundo tem que trabalhar: quem não trabalhar não sobrevive, né?” (Válter, 30 anos).

Outra função do trabalho apontada pelos trabalhadores entrevistados foi a de colocá-los em movimento, tirá-los de casa. Neste sentido, o trabalho, como colocam Salanova et al. (1996), além de estruturar o tempo das pessoas, funciona como uma fonte de auto-respeito e de reconhecimento pelos outros. Zaluar (1994) afirma que a categoria "trabalhador" é usada para indicar um valor moral superior das pessoas assim referidas em relação a outras rotuladas de "vagabundos", "malandros" ou "bandidos".

\footnotetext{
"Melhores condições de vida, como um sustento melhor e também pra não ficar parado dentro de casa e as pessoas na rua te olhando, te discriminando como vagabundo. Porque a pessoa que não trabalha é discriminada, né? Como vagabundo" (Fábio, 20 anos).
}

Entretanto, se a representação do trabalho como entidade ontológica apresentou uma série de elementos positivos, o trabalho realizado na construção civil foi descrito como "arriscado", "pesado", "desvalorizado", "discriminado" e "sem futuro". "Tudo só é risco na construção aí. Tudo é arriscado. A pessoa trabalha, mas tudo é arriscado" (Rui, 30 anos).; "Tem pessoas que têm um pouco de preconceito, acha só porque a pessoa trabalha de pedreiro, nessa função de construção civil, que a pessoa é burro, ignorante, não sei o quê, nem quer muita conversa com a pessoa" (Válter, 30 anos). Essa imagem negativa do trabalho na construção civil fica ainda mais evidente quando os trabalhadores, quando lhes foi perguntado se gostariam que algum filho viesse a desenvolver tais serviços, negaram veementemente: "Eu quero que minha filha siga uma profissão melhor de que... não passe pelo que passei" (Anilton, 34 anos).

A desvalorização e o preconceito para com as pessoas que trabalham na construção civil são tão intensos, que um trabalhador relatou que não deixaria a sua carteira de trabalho ser assinada como pedreiro. Tais elementos corroboram Kelly-Santos e Rozemberg (2006), que apresentam relatos de trabalhadores da construção civil cuja auto-imagem é de pessoas abandonadas, "escravos da sociedade", que têm vergonha de se identificar como trabalhadores desse ramo de atividade. A insatisfação dos trabalhadores apareceu também no relato das situações de interação com os chefes e patrões, descritas como causadoras de incômodo pela forma humilhante como eram tratados.

\footnotetext{
"Rapaz, eu acho que essas atividade aí incomodava sim! Acho que é muito humilhante pra você. (...). Aí o engenheiro chegou, ele não aprovou não, entendeu? Aí ele invés de chegar numa boa, chegou e falou assim: 'Venha cá, isso aqui é um cocô ou é uma bosta?'” (Alberto, 19 anos).
}

A representação dos trabalhadores acerca dos chefes e patrões revela a imagem de indivíduos que não tratam o trabalhador como igual, humilhando-os, e que não valorizam o seu trabalho. Corroborando esse pensamento, o representante do sindicato entrevistado afirmou que:

\footnotetext{
“... os patrões da construção civil ainda são do tempo da escravatura, eles não mudaram muito. Eles não vêem muito o trabalhador como um parceiro deles, vêem o trabalhador como uma peça".
}

Nessa relação, conforme Zaluar (1994), são atualizados os conflitos entre o capital e o trabalho, quando invocada a condição de subalterno e dependente do trabalhador frente ao patrão. Segundo a 
autora, o autoritarismo é um problema que marca as relações de trabalho no Brasil, fazendo emergir o ethos masculino que clama pela democratização das relações de trabalho.

Todos esses fatores levam os trabalhadores a demonstrarem insatisfação com a atividade desenvolvida, afirmando que, se tivessem oportunidade, trocariam de serviço.

\begin{abstract}
"Se me desse oportunidade, eu gostaria [de trocar de serviço]. Sei lá, encarregado de alguma coisa. Porque tem um salário legal e também você... Tudo bem, você vai ficar subalterno a alguém, mas não a todo mundo, tá entendendo? E a pessoa que trabalha como peão, ele é mandado por todo mundo" (Laércio, 24 anos).
\end{abstract}

Esse lugar ocupado pelo "peão" - subalterno a todos os outros trabalhadores - intensifica o sentimento de "não-valor" por parte dos trabalhadores da construção civil. Eles entendem que a falta de estudo não lhes permite pleitear outros serviços, sendo colocada como principal fator limitador de uma melhor inserção no mundo do trabalho. $\mathrm{O}$ fato de não terem tido condições de alcançar uma melhor escolaridade termina por justificar certo sentimento de impotência e resignação diante das péssimas condições de trabalho e dos baixos salários. O estudar foi apontado pelos trabalhadores como algo que " $d a ́$ poder às pessoas", possibilitando se comunicar melhor, tomar decisões mais acertadas e conseguir melhores empregos. Assim sendo, estudar se configura como um pré-requisito para conseguir ascender socialmente, meio através do qual esperam que seus filhos possam alcançar uma condição melhor que a deles. Sobre essa questão, Kelly-Santos e Rozemberg (2006) colocam que os trabalhadores tendem a reproduzir uma lógica utilitária da educação, recorrendo "às metodologias educativas para reproduzir a racionalidade do poder hegemônico: educar para instruir, para prevenir e para produzir. Isso permite a reprodução e perpetuação do conflito entre as relações sociais" (p. 980).

Essa idéia parece pertinente, pois, apesar da insatisfação dos trabalhadores com as condições de trabalho, não se verifica uma maior mobilização para melhorá-las. A classe trabalhadora da construção civil foi descrita como desunida. Essa desunião pode ser resultado da alta rotatividade e fragmentação do processo produtivo em que estão inseridos, o que dificulta sua identificação como categoria e conseqüente organização em entidades de classe. Quando indagados sobre o sindicato, disseram que sabiam de sua existência, mas que não participavam, pois não tinham a carteira de trabalho assinada.

Destarte, pela forma como se inserem no ramo e pela falta de implicação e satisfação demonstrada em relação ao trabalho realizado, pode-se dizer que os trabalhadores informais da construção civil não são exatamente uma categoria, eles estão categoria. Isto atomiza a situação deles diante do ramo como um todo, fragilizando ainda mais sua posição na relação com o empregador, pois esse trabalhador não se sente membro do grupo, nem vislumbra alguém que o possa representar.

Diante dos resultados, o trabalho na construção civil parece se constituir no "último recurso" buscado para garantir a sobrevivência por uma população predominantemente de homens com características de exclusão social como a cor da pele negra, baixo nível educacional e socioeconômico. Os trabalhadores demonstram não gostar das atividades que desenvolvem, não estar satisfeitos com as condições de trabalho, com os salários, nem com a relação estabelecida com os chefes e patrões. Apesar disso, sujeitam-se a trabalhar no ramo, pois é o único espaço onde encontram serviço: "Eu procurei trabalho, entendeu? Só que eu não encontrei. Aí eu recorri a isso mesmo. Foi o que eu achei. Eu peguei e fui pra isso" (Alberto, 19 anos).

A construção civil parece possibilitar uma oportunidade de emprego para alguns jovens que, ao conseguirem um serviço melhor, abandonam-na. Por exemplo, Alberto, tendo oportunidade, não quis continuar a trabalhar no ramo; Fábio investiu em uma mudança de cidade no intuito de conseguir melhor inserção laboral; e Valter voltou a trabalhar na profissão com a qual se identificava (segurança patrimonial). Contudo, é importante pontuar que, por serem trabalhadores acidentados, suas representações podem estar enviesadas pela experiência do acidente.

Simão, o trabalhador mais velho do grupo entrevistado, caracteriza o outro extremo das representações do trabalho na construção civil: valoriza o seu trabalho, gostaria que seu filho seguisse seu exemplo e sente orgulho da profissão.

"É uma profissão que eu acho bonita mesmo, que gosto mesmo. Como há pouco instante eu vim da rua, passei e vi um pedreiro ali trabalhando. Um negócio bonito, tudo nivelado, esquadrejado! Aí eu acho bonito, né? A gente vê uma parede de bloco assim velha, toda feia, depois aí vê o cara botar um reboco, nivelar toda, eu acho bonito, como eu achei” (Simão, 61 anos). 
Essa fala de Simão pôde ser confirmada na observação participante. Sempre bem-humorado, demonstrava um grande prazer em desenvolver as atividades exigidas por sua função de pedreiro. A todo o momento deixava transparecer o seu orgulho de estar realizando, apesar de seus 61 anos, todo tipo de serviço. Dizia que tinha de agradecer a Deus por ter saúde, "a coisa mais importante na vida". A saúde surge, assim como descrito por Sarti (1996), assumindo um status de valor moral, fazendo com que Simão, apesar da idade avançada, sinta-se forte e orgulhoso por poder trabalhar.

Se a representação do trabalho na construção civil já apresenta uma série de aspectos negativos, o fato de ele ser realizado na informalidade vem macular ainda mais tal representação. Expressões como "perda de tempo", "trabalho em vão", "trabalho sem valor", "trabalho inútil", e "trabalho à toa" foram usadas para se referir ao trabalho informal. Essas enunciações remetem à importância atribuída aos direitos trabalhistas e previdenciários garantidos pela formalização do contrato de trabalho. Tais expressões remetem, também, à importância simbólica que a carteira assinada representa na valorização do trabalho e do trabalhador. Esse aspecto é ilustrado por Alberto quando compara os que possuem carteira assinada com aqueles que não a possuem.

\begin{abstract}
"Os pedreiro mesmo que era carteira assinada, eles tinha mais direito de que a gente que não era carteira assinada. Quando era feriado assim, ele não vinha. A gente tinha que ir, entendeu? Ele bateu o horário dele, oh! Se saía logo! A gente não, se a gente batesse nosso horário ali, e chegasse algum caminhão com alguma coisa pra gente descarregar, a gente tinha que descarregar. Ele chegava, ainda assinava um papel lá, provando que tinha chegado, a hora que chegou, a hora que saiu. A gente chegava não tinha nada, não tinha nada disso pra gente, entendeu? Era tipo uma pessoa assim inútil, a gente não tinha direito a nada assim" (Alberto, 19 anos).
\end{abstract}

É possível perceber que Alberto, na posição de trabalhador informal, sentia-se inferiorizado em relação aos demais, que tinham contrato formal de trabalho. Essa situação reflete bem o processo de afirmação da cidadania no país, que transformou a carteira de trabalho em uma espécie de nascimento cívico das pessoas (Santos, 1987), levando aqueles que não a têm a ocuparem um lugar de "cidadãos de segunda categoria". Esse tipo de exclusão pode gerar um "sofrimento ético-político" (Sawaia, 1999), caracterizado, especialmente, pela dor que surge da situação social de ser tratado como inferior, subalterno, sem valor, apêndice inútil da sociedade.

Pode-se apreender que esses trabalhadores experienciam um tipo de violência que se materializa na infração de princípios fundamentais e direitos no trabalho, configurando uma relação social de dominação, exploração, de negação do ser humano. Tais situações carregam um profundo sentido de negatividade, já que não contribuem para o desenvolvimento da pessoa nem para o aperfeiçoamento do gênero humano.

A impossibilidade de se aposentar foi apontada como uma importante perda resultante do trabalho sem carteira assinada. Esse fato parece evidenciar, principalmente, a preocupação dos trabalhadores mais idosos com o envelhecimento e conseqüente diminuição da capacidade produtiva, além da maior dificuldade de conseguir trabalho. A preocupação com o futuro vem contrastar com o contexto em que os trabalhadores se encontram, no qual, como colocado por Castel (1998a), são convocados a "viver o dia-a-dia", o aqui e o agora, já que convivem com as incertezas e instabilidades da informalidade. O caso de Simão ilustra bem essa situação, pois, estando com uma idade avançada e não tendo conseguido se aposentar, tem que trabalhar na informalidade, pois não consegue inserção formal na construção civil.

Quando indagados sobre uma possível vinculação ao Instituto Nacional de Seguro Social - INSS como autônomos, os trabalhadores demonstraram reconhecer a importância, mas denunciaram a impossibilidade, devido à incerteza de ganhos.

\footnotetext{
"Paguei uns três ano [o INSS como autônomo], depois abandonei porque nem sempre a pessoa acha serviço assim direto, né? A pessoa que trabalha assim avulso, trabalha às vezes um mês, dois meses direto depois pára, que não acha, não tem. Entendeu?! Aí o problema é esse (Simão, 61 anos).
}

Outro fator negativo associado ao trabalho informal foi a não-cobertura previdenciária em caso de acidentes, o que, possivelmente, está ligado à vivência concreta, por parte desses trabalhadores, de situações de acidentes de trabalho:

"Eu acho que a carteira assinada, eu acho melhor, porque a pessoa tá seguro, não sabe? Pode ser na doença... a pessoa se se acidentar tem o direito de receber o mês e a pessoa avulso não tem condições" (Anilton, 34 anos). 
Os trabalhadores consideravam "normal" trabalhar sem a carteira assinada, visto que a falta desta não se mostrava uma novidade, mas uma constante nas várias atividades desenvolvidas durante a vida laboral. Alberto chegou a afirmar que, em algumas situações, como no caso de pequenos serviços, ele achava que não era preciso assinar a carteira. Esse comportamento derivava do fato de que, segundo os trabalhadores, o registro em carteira de pequenos períodos de trabalho "suja" o documento, levando os patrões a pensarem que o trabalhador "não presta", já que não fica em emprego nenhum. Por outro lado, a ausência de registro em carteira é vista como um prejuízo para o trabalhador, uma vez que ele fica sem ter como comprovar suas experiências. Isso dificulta tanto o trabalhador conseguir ser "classificado" para trabalhar em uma função mais especializada, a exemplo de pedreiro, carpinteiro e pintor, quanto realizar outros trabalhos na informalidade. Nesse sentido, corroborando Sorj (2000), a rede social se constitui como importante fator para aquisição de trabalho, muitas vezes sendo o ponto de partida para manter o trabalhador na ativa: “... o cara deve dar graças a Deus, ter um bom conhecimento, trabalhar direito, pra poder uma pessoa informar a outra" (Simão, 61 anos).

Apesar de a representação do trabalho informal apresentar, predominantemente, aspectos negativos, alguns pontos positivos foram também relatados, como a possibilidade de ganhar mais e de realizar diferentes serviços. Um trabalhador (Paulo) chegou a dizer que preferia trabalhar sem carteira assinada, denotando descrédito do cumprimento das leis trabalhistas. No entanto, os outros trabalhadores foram incisivos em afirmar que, apesar de acharem que o trabalhador informal pode vir a ganhar mais, preferem trabalhar com carteira assinada. Por conseguinte, é possível afirmar que a inserção informal no mundo do trabalho, para os trabalhadores (exceto para Paulo), ocorreu não como uma escolha, mas como resultado de uma circunstância coercitiva que os obrigou a buscar serviço, mesmo que sem um contrato formal de trabalho.

\section{CONSIDERAÇÕES FINAIS}

Diante dos resultados do artigo que ora se conclui, observa-se que, não obstante o trabalho ser representado como uma dimensão central na vida dos trabalhadores, o trabalho informal na construção civil foi representado através de um maior número de conceitos negativos do que positivos. Isto pode ser atribuído ao reconhecimento, por parte dos trabalhadores, da precarização do trabalho gerada pela inserção informal. Para eles, a carteira de trabalho assinada está associada, sobretudo, à segurança de uma renda certa, à aposentadoria remunerada, ao amparo em caso de acidente de trabalho e ao respeito ao trabalhador como cidadão. Ser informal foi representado como a negação de ser formal: o trabalhador formal tem direitos e o informal não tem; o formal é registrado, "fichado", o informal ("avulso") não; o formal é "estável”, o informal não. Enquanto o formal é e tem, o informal não é e não tem.

A tendência a justificar a ocupação desse "nãolugar" (Augé, 1994) de não ser e não ter através de alguns conceitos de cunho claramente positivos, tendo destaque o "ganhar mais", traz a idéia de comportamentos que podem ser interpretados como de resignação e abnegação. Mesmo com tais comportamentos, toda a precarização por eles atribuída à informalidade se apresenta como o alicerce que torna conflitante a busca pela sobrevivência e sustento da família: se por um lado eles mantêm, de forma ativa, seu papel de provedor da família (Zaluar, 1994), por outro, constrangidos pela necessidade, eles se apresentam como corpo submisso (Foucault, 1988) no canteiro de obras.

Uma potencial limitação do estudo está no fato de as entrevistas em profundidade terem sido conduzidas apenas com trabalhadores acidentados. Por já terem sofrido acidente de trabalho, esses trabalhadores podem ter apresentado respostas enviesadas, o que não foi possível investigar, pois não houve um grupo de trabalhadores não-acidentados que pudesse servir de base de comparação. Outras questões que surgiram durante o estudo, a exemplo de tópicos como gênero, raça, migração e o problema da drogadição entre trabalhadores da construção civil - principalmente o alcoolismo -, apesar de relevantes, não foram tratadas, pois não constituíam objetivos da pesquisa.

Como elemento de reflexão final, salienta-se a importância da realização de pesquisas acerca das "violências" relacionadas ao trabalho na construção civil. Entende-se que os resultados deste estudo demonstram como os trabalhadores aí inseridos vivenciam uma série de situações, que lhes cerceiam o usufruto de direitos constitucionalmente assegurados, excluindo-os do pleno gozo da cidadania.

\section{REFERÊNCIAS}

Augé, M. (1994). Não lugares: introdução a uma antropologia da supermodernidade. Campinas: Papirus.

Azevedo, J. S. G. (1999). Mudanças no Padrão de Ocupação na RMS. Bahia: Análise e Dados, 8(4), 9-26. 
Barros, R. P. \& Mendonça, R. (1996). Os determinantes da desigualdade no Brasil. Em R. P. Barros \& R. Mendonça (Orgs.), A economia brasileira em perspectiva (pp. 412-473). Rio de Janeiro: IPEA

Borges, A. \& Druck, M. G. (1993). Crise global, terceirização e a exclusão do mundo do trabalho. Caderno $C R H, 6(19), 23-45$.

Borges, H. \& Martins, A. (2004). Migração e sofrimento psíquico do trabalhador da construção civil: uma leitura psicanalítica. PHISIS: Revista de Saúde Coletiva, 14(1), 129-146.

Castel, R. (1998a). As metamorfoses da questão social: uma crônica do salário. Petrópolis: Vozes.

Castel, R. (1998b). As metamorfoses do trabalho. Em J. L. Fiori, M. S. Lourenço \& J. C. Noronha (Orgs.), Globalização: o fato e o mito (pp. 147-163). Rio de Janeiro: EdUERJ.

DIEESE - Departamento Intersindical de Estatística e Estudos Sócio-Econômicos. (2001). Os trabalhadores e a reestruturação produtiva na construção civil brasileira. São Paulo: AUTOR.

Fagundes, T. L. Q. (1994). Trabajo, estrategias de supervivencia e la salud de los niños e las niñas en los paises en las regiones de las Americas. Washington: PAHO.

Filgueiras, L. A. M., Druck, G. \& Amaral, M. F. (2004). O conceito de informalidade: um exercício de aplicação empírica. Caderno CRH, 17(41), 211-229.

Foucault, M. (1988). Vigiar e punir: histórias da violência nas prisões. Rio de Janeiro: Vozes.

Gorz, A. (1982). Adeus ao proletariado. Rio de Janeiro: Forense.

Jovchelovitch, S. (1995). Vivendo a vida com os outros: intersubjetividade, espaço público e Representações Sociais. Em P. A. Guareschi \& S. Jovchelovitch (Orgs.), Textos em representações sociais (pp. 63-85). Petrópolis: Vozes.

Kelly-Santos, A. \& Rozemberg, B. (2006). Estudo de recepção de impressos por trabalhadores da construção civil: um debate das relações entre saúde e trabalho. Cadernos de Saúde Pública, 22(5), 975-985.

Menezes, W. F. \& Carrera-Fernandez, J. (1998). Ocupação e informalidade no mercado de trabalho da Região Metropolitana de Salvador. Conjuntura \& Planejamento, 2(45), 5-12.

Montali, L. (2000). Família e Trabalho na Reestruturação Produtiva: ausências de políticas de emprego e deterioração das condições de vida. Revista Brasileira de Ciências Sociais, 15(42), 57-71.

Moscovici, S. (1978). A Representação Social da Psicanálise. Rio de Janeiro: Zahar.

Mourão, L. \& Borges-Andrade, J. E. (2001). Significado do Trabalho: caminhos percorridos e sinalização de tendências [CD-ROM]. Em Anais do $25^{\circ}$ Encontro Anual da ANPAD. São Paulo: Portifólio.
Offe, C. (1994). Capitalismo desorganizado. São Paulo: Brasiliense.

Ringen, K., Seegal, J. L. \& Weeks, J. L. (1998). Construction. In J. M. Stellman (Ed.), Enciclopedia de Salud y Seguridad en el Trabajo. Geneva, International Labour Office. Retrieved in June 17, 2003, from http://www.mtas.es/insht/EncOIT/tomo3.html

Salanova, M., Gracia, F. J. \& Peiró, J. M. (1996). Significado del Trabajo y Valores Laborales. Em J. M. Pieró \& F. Prieto (Orgs.), Tratado de Psicología del Trabajo - Volume II: Aspectos Psicosociales del Trabajo (pp. 35-63). Madrid: Sintesis Psicología.

Santana, V. S. \& Oliveira, R. P. (2004). Saúde e trabalho na construção civil em uma área urbana do Brasil. Cadernos de Saúde Pública, 20(3), 797-811.

Santana, V. S., Nobre, L. \& Waldvogel, B. C. (2005). Acidentes de trabalho no Brasil entre 1994 e 2004: uma revisão. Ciência \& Saúde Coletiva, 10(4), 841-855.

Santos, W. G. (1987). Cidadania e justiça: a politica social na ordem brasileira. Rio de Janeiro: Campus.

Sarti, C. A. (1996). A família como espelho: um estudo sobre a moral dos pobres. Campinas: Autores Associados.

Sawaia, B. B. (1999). O sofrimento ético-político como categoria de análise da dialética exclusão/inclusão. Em B. B. Sawaia (Org.), As artimanhas da exclusão: análise psicossocial e ética da desigualdade social (pp. 97-118). Petrópolis: Vozes.

SESI - Serviço Social da Indústria. (1998). Projeto SESI na Indústria da Construção: diagnóstico da Mão-de-Obra do Setor da Construção Civil. Brasília: SESI/DN.

Sorj, B. (2000). Sociologia e trabalho: mutações, encontros e desencontros. Revista Brasileira de Ciências Sociais, 15(43), 25-34.

Spink, M. J. P. (1995a). Desvendando as teorias implícitas: uma metodologia de análise das Representações Sociais. Em P. A. Guareschi \& S. Jovchelovitch (Orgs.), Textos em representações sociais (pp. 117-145). Petrópolis, RJ: Vozes.

Spink, M. J. P. (1995b). O estudo empírico das Representações Sociais. Em M. J. P. Spink (Org.), O Conhecimento no Cotidiano: as representações sociais na perspectiva da psicologia social (pp. 85-108). São Paulo: Brasiliense.

Wagner, W. (1998). Sócio-gênese e características das representações sociais. Em A. S. Moreira \& D. C. Oliveira (Orgs.), Estudos interdisciplinares de representação social (pp. 3-38). Goiânia: AB.

Zaluar, A. (1994). A máquina e a revolta: as organizações populares e o significado da pobreza. São Paulo: Brasiliense.

Recebido em 20/12/2006 Aceito em 05/09/2007

\footnotetext{
Endereço para correspondência : Roberval Oliveira. Universidade Federal do Recôncavo da Bahia-UFRB, Centro de Ciências da Saúde-CCS. Rua do Cajueiro, s/n, Cajueiro, CEP 44574-490, Santo Antônio de Jesus-BA. E-mail: robervaloliveira@gmail.com
} 